\title{
ESTUDO LÉXICO-SEMÂNTICO DE UM PROCESSO CRIME DE DEFLORAMENTO DE 1914
}

\author{
Jéssica Pâmela Bomfim Silva $^{1}$; Rita de Cássia Ribeiro de Queiroz ${ }^{2}$ \\ 1. Bolsista PIBIC/CNPq, Graduanda em Letras Vernáculas, Universidade Estadual de Feira de Santana, e-mail: \\ jelbomfim@live.com \\ 2. Rita de Cássia Ribeiro de Queiroz, Departamento de Letras e Artes, Universidade Estadual de Feira de Santana, \\ e-mail:rcrqueiroz@uol.com.br
}

PALAVRAS-CHAVE: Auto de defloramento. Estudo léxico-semântico. Sexualidade.

\section{INTRODUÇÃO}

O léxico é um sistema pelo qual podemos nomear, através de palavras, tudo o que nos cerca, sendo um tesouro linguístico, uma "porta" pela qual podemos adentrar e conhecer vários aspectos de um povo: a cultura, a história, as leis, os costumes etc. Diante disso, ao analisarmos o léxico, estudamos, também, "[...] a história do povo [...]" (ABBADE, 2006, p.213), pois o homem "bebe" da fonte lexical para significar e fazer a sua história.

Dito isso, o presente trabalho teve como objetivos levantar e analisar o vocabulário da sexualidade constante no Processo Crime de Defloramento, um documento lavrado em 1914 que está sob a guarda do Centro de Documentação e Pesquisa (CEDOC), localizado na Universidade Estadual de Feira de Santana (UEFS). Através desse documento, foi possível enveredar por um período histórico, trazer à tona as lexias da sexualidade produzidas entre 1914 a 1924 que, muitas vezes, são desconhecidas da atualidade, bem como a história de Lindaura Maria de Jesus, que representa muitas mulheres que foram desvirginadas nesse período, julgadas e mal vistas pela sociedade só porque não cumpriram a convenção social de que deveriam permanecer virgens até o casamento.

\section{METODOLOGIA}

Para o estudo léxico-semântico do Processo Crime de Defloramento foram seguidos alguns critérios baseados em Barreto (2013) e Queiroz (2012):

1. As lexias são apresentadas em letras maiúsculas e em negrito, seguidas pela classificação genérica da categoria gramatical a que pertencem;

2. As lexias compostas foram classificadas como locução;

3. As entradas dos nomes (substantivos e adjetivos) são feitas pelo masculino e feminino singular;

4. As entradas dos verbos são feitas pelo infinitivo;

5. Após a entrada e a classificação apresentamos a significação da lexia no contexto específico, seguida de um exemplo do texto e todas as demais indicações presentes no processo crime e os respectivos fólios e linhas;

6. Os exemplos são apresentados entre aspas, com a lexia destacada em negrito. 


\section{RESULTADOS E/OU DISCUSSÃO}

A partir da leitura e da análise do documento, foram estabelecidos oito macrocampos, seis microcampos e 28 lexias relativos ao campo lexical da sexualidade, a saber:

1- Macrocampo dos Órgãos Sexuais - Microcampo: genérico, partes da ofendida e partes do ofensor;

2- Macrocampo das ações;

3- Macrocampo das intenções sexuais;

4- Macrocampo das relações sexuais;

5- Macrocampo das ações jurídicas;

6- Macrocampo dos crimes sexuais;

7- Macrocampo dos qualificadores - Microcampo: Sobre a ofendida e Sobre o ofensor;

8- Macrocampo dos envolvidos no crime - Microcampo: com a ofendida e com o ofensor.

A seguir, trouxemos apenas dois exemplos de macrocampos: órgãos sexuais e crimes sexuais, juntamente com as lexias, as significações e os contextos que aparecem no texto do Processo Crime:

\section{MACROCAMPO DOS ÓRGÃOS SEXUAIS}

\section{Microcampo: Partes da ofendida}

HÍMEN - s.m 'Prega formada pela mucosa e que fecha parcialmente o orifício externo da vagina.'

"[...] o hymnem apresenta so-/ lução de continuidade, cuja data escapa a ava-/ liação $[\ldots] "(f .60 r, 1.28-30)$

HONRA - s.f. 'Vagina'

"Diz Avelino Jose da Costa, lavrador re-/ sidente no districto de Almas deste/ termo, que tendo sido offendida/ em sua honra a sua filha menor/ de nome Lindaura Maria de Jezus [...]" (f.9r, 1.7-11)

\section{Microcampo: Partes do ofensor}

CORPO DURO E ELÁSTICO - s.m. 'Pênis'

"[...] Ao pri-/ meiro sim; segundo um/ corpo duro e elastico [...]” (f.15v, 1.25-27)

MEMBRO VIRIL - s.m 'Pênis'

"[...] Ao pri-/ meiro sim; segundo um/ corpo duro e elastico tal/ como um membro veriril/ em erecção [...]" (f.15v, 1.25-29)

\section{MACROCAMPO DAS ACCÕES}

CASAR - v.t.d 'Unir por casamento'

“[...] Luiz de Assis lhe/ discera, que João ia se ca/ sar com Lindaura [...] (f.39v, 1.4-6)

"[...] Perguntado/ como sabe ter o denuncia-/ do compromettido a se / casar com Lindaura? (f.41v, 1.4-7)

"[...] João/ lhe disse que ia casar se/ e elle testimunha lhe disse/ que assim era muito/ bonito [...]" (f.46r, 1.26-30) 
"[...] ouvira/ de Tiburcio que o acusa-do/ presente lhe havia/ dito que ia se casar com/ Lindaura porque devia/ a honra della." (f.49r, 1.18-23)

REPARAR O MAL - loc. verb. 'Reparar a ofensa do defloramento e/ou estupro através do casamento'.

"[...] porque se é doloroso e contristador o facto/ de espiritos perversos e libidinosos arrastarem/ para a prostituição a donzellas inesperi-/ entes, e não lhes queiram reparar o mal [...]" (f.59r, 1.15-17)

\section{MACROCAMPO DOS CRIMES SEXUAIS}

DEFLORAMENTO - s.m. 'Desvirginamento'. “[...] Considerado pelo querellado para a/ defeza dos seus direitos, fomos cautellosos em/ ouvil-o previamente e convictos de não ter/ sido elle o auctor do defloramento de Lindaura/ Maria de Jesus [...]" (f.59r, $1.9-13)$

DEFLORAR - v.t.d. 'Perder a virgindade'.

"[...] João Vasconcellos/ por ter este em dias do mez/ de junho no corrente anno, deflorado/ a menor Lindaura Maria de Jesuis [...]" (f.24r, 1.29-33)

DESVIRGINAR - v.t.d 'Perder a virgindade'. "[...] lhe dissera que o acusa-/ do presente lhe havia/ communicado, que muito/ breve se casaria com Lin-/ daura Maria de Jesus/ a quem havia n'aquela/ occasião desvirginado [...]" (f.35r, 1.26-32)

PRATICAR ATOS INDIGNOS - loc. verbal 'Prática de atos que causam dano a outrem'. "[...] João Vasconcellos há/ dois annos ha muito tempo que elle/ lhe illudia com promessas de/breve cazamento com o fim/ de praticar com ella actos/ indigno [...]" (f.16v, 1.11-15)

\section{CONSIDERAÇÕES FINAIS}

O estudo do léxico da sexualidade, no documento jurídico, nos possibilitou resgatar lexias e sentidos já não usados na atualidade, como por exemplo: defloramento (como sinônimo de desvirginamento), honra (denominando o órgão sexual feminino) e corpo duro e elástico (referindo-se ao órgão sexual masculino). Em vista disso, podemos concluir que essas mudanças fazem parte do processo de constituição do léxico, sendo normais os surgimentos e os desaparecimentos de lexias, expressões e sentidos. Tal estudo nos propiciou, também, conhecermos mais sobre a sociedade no início do século XX, a visão machista a respeito de uma menor ser desvirginada e mãe solteira.

\section{REFERÊNCIAS}

ABBADE, Celina Márcia de Souza. O estudo do léxico. In: TEXEIRA, Maria da Conceição Reis; QUEIROZ, Rita de Cássia Ribeiro de; SANTOS, Rosa Borges dos (Org.). Diferentes perspectivas dos estudos filológicos. Salvador: Quarteto, 2006. p. 213-225. 
BARRETO, Josenilce Rodrigues de Oliveira. Edição semidiplomática e estudo do vocabulário de uma Ação de Desquite do início do século XX. Cadernos do CNLF, Rio de Janeiro: CiFEFiL, vol. XVII, n.3, p. 81-93, ago. 2013.

QUEIROZ, Rita de Cássia Ribeiro de. Filologia e lexicologia: A edição e o estudo do vocabulário de autos de defloramento. LING.- Est. e Pesq, Catalão-GO, vol. 16, n. 2, p. 15-28, jul./dez. 2012. 